\title{
The Influence of New Product Development Based on External Technology Acquisition
}

\author{
Zhihui Jing \\ School of Management, \\ Guangxi University of Science and Technology \\ Liuzhou, China \\ E-mail: 517239651@qq.com
}

\author{
Shiping Guan \\ School of Management \\ Guangxi University of Science and Technology \\ Liuzhou, China
}

\author{
Guilian Liu \\ School of Management \\ Guangxi University of Science and Technology \\ Liuzhou, China
}

\begin{abstract}
With the number of high tech industries in China in 1995 - 2013, it estimates that foreign advanced technology and domestic technology have influence on the development of new products. By comprehensive using the dynamic econometrics which include of the theory of unit root test, co-integration analysis and Granger causality test to verify. The results show that the introduction of foreign technology and domestic technology have an impact on the development of new products of high tech enterprises in China.
\end{abstract}

Keywords-foreign technology introduction; purchasing domestic technology; absorptive capacity; new product development

\section{INTRODUCTION}

Because of the progress of science and technology, the cycle of product development has greatly been shortened, at the same time,the development of products becomes more and more important. Enterprises always improve the new product development capabilities through internal research and development or external access. But the internal R \& D needs a considerable $\mathrm{R}$ \& $\mathrm{D}$ strength and investment high $\mathrm{R} \& \mathrm{D}$ funds. Thus it's difficult to adapt to the rapid growth of market demands just depending on the internal resources of innovation activities. Based on the perspective of external technology research, This paper will explore the impact of external technology acquisition mode on the new product development in two ways which are the introduction of foreign technology and domestic technology purchase.The research will have a profound impact on how the enterprises use external technical resources to improve their ability to product innovation effectively.

\section{THEORY AND HYPOTHESES}

A. Product Performance of External Technology Acquisition

There are two ways can be used by enterprise to gain external technology, that is, the introduction of foreign technology and purchase of domestic technology[1]. Foreign technology introduction is the cost of buying foreign technology, the purchase of domestic technology refers to the cost of buying other units of scientific and technological achievements. Including product design, process, drawings, formulation, patent technical information, and purchase of key equipment, instrument, prototypes, samples of expenses.

The advantage of external technology is that it not only narrows the technology gap in a short time to make up for the short board, but also can reduce the risk of innovation activities, meanwhile it is more advantageous to launch products and services [2].

1) Product innovation of foreign technology introduction.

Liu and Buck believe that the speed of new product development of company can be directly accelerated via the introduction of technology[3]. By using the dynamic econometric theory, Chen Ao's empirical analysis based on the data of the large and medium-sized industrial enterprises in our country found the introduction of technology are benefits to improve the product innovation performance of Chinese enterprises [4]. Li Wuwei also empirically analyzes the direct positive impact on the innovation performance of high tech industrial products in China[5].

2) Purchase product innovation of domestic echnology.

Olso manual pointed out that there are two advantages in purchasing of technology: it is not only a simple and low-cost way to obtain technology, but also a quick and easy way to transfer technology. Chen Ao's empirical analysis of domestic technology purchase have a positive impact on enhancing the ability to the new product development of enterprises ${ }^{[4]}$.

\section{B. Absorptive Capacity and External Technology Acquisition}

Absorptive capacity refers to the capabilities that discover the new information, and apply them in the business way through absorbing them [6]. New product development cannot be separated from the external resources, technology and knowledge, so that the ability of enterprise itself has a large 
extent to determine its ability of obtaining the external technology $[7,8,9]$. The more absorptive capacity, the more the value of the external information, the more effective the existing knowledge of integration and knowledge creation [10], and then applied to new product development.

\section{MODEL ANALYSES}

\section{A. Measurement Method Choice}

Co integration analysis is to determine the order of a single integer, the number of variables in a single integer order, or the number of variables in different order after a combination of conditions, there may be a long-term equilibrium relationship. On the basis of the above analysis, the relationship between the variables and the variables can be judged more comprehensively. The research method of this paper is to study the relationship between the absorption capacity, foreign technology introduction, domestic technology purchase and new product development by using the Grainger causality test and co integration analysis.

\section{B. Indicators and Data Sources}

Taking account of the lag effect of foreign technology introduction and domestic technology purchase on the actual patent output, and the patent licensing is also reflected the efforts in the innovation ability of enterprises, therefore, the actual patent output of this paper is replaced by the amount of enterprise patent licensing. Through searching "China's high tech Industry Statistical Yearbook" to get 1995-2013 years of large and medium-sized high-tech enterprise absorptive capacity (XS), foreign technology introduction (GWYJ), domestic technology purchase (GNGM) and patent licensing (ZLSQ) data.

TABLE I. RESULTS OF UNIT RoOT TEST

\begin{tabular}{|c|c|c|c|c|c|}
\hline Variable & $\begin{array}{l}\text { ADF test } \\
\text { statistic }\end{array}$ & $\begin{array}{l}1 \% \\
\text { level }\end{array}$ & $\begin{array}{c}5 \% \\
\text { level }\end{array}$ & $\begin{array}{l}10 \% \\
\text { level }\end{array}$ & Conclusion \\
\hline XS & 16.06852 & $\begin{array}{l}- \\
3.504727 \\
\end{array}$ & $\begin{array}{l}- \\
2.893956\end{array}$ & $-\overline{2.584126}$ & $\begin{array}{l}\text { Non- } \\
\text { stationary }\end{array}$ \\
\hline $\mathrm{D}(\mathrm{XS})$ & - 3.864262 & $-\overline{4.065702}$ & $\begin{array}{l}- \\
3.461686\end{array}$ & $\begin{array}{l}- \\
3.157121\end{array}$ & Stationary \\
\hline GWYJ & $\begin{array}{l}- \\
2.178264\end{array}$ & $\begin{array}{l}- \\
3.504727\end{array}$ & $\begin{array}{l}- \\
2.893956\end{array}$ & $\begin{array}{l}- \\
2.584126\end{array}$ & $\begin{array}{l}\text { Non- } \\
\text { stationary }\end{array}$ \\
\hline $\mathrm{D}(\mathrm{GWYJ})$ & $\begin{array}{l} \\
31.82899\end{array}$ & $\begin{array}{l}- \\
3.504727\end{array}$ & $\begin{array}{l} \\
2.893956\end{array}$ & $\begin{array}{l}- \\
2.584126\end{array}$ & Stationary \\
\hline GNGM & $\begin{array}{l}- \\
0.134799\end{array}$ & $\begin{array}{l}- \\
3.504727\end{array}$ & $\begin{array}{l}- \\
2.893956\end{array}$ & $\begin{array}{l}- \\
2.584126\end{array}$ & $\begin{array}{l}\text { Non- } \\
\text { stationary }\end{array}$ \\
\hline $\mathrm{D}(\mathrm{GNGM})$ & 50.49858 & 3.504727 & $-\overline{2.893956}$ & $-\overline{2.584126}$ & Stationary \\
\hline ZLSQ & $\begin{array}{l}- \\
0.885769\end{array}$ & $\begin{array}{l}- \\
3.504727\end{array}$ & $\begin{array}{l}- \\
2.893956\end{array}$ & $-\overline{2.584126}$ & $\begin{array}{l}\text { Non- } \\
\text { stationary }\end{array}$ \\
\hline D(ZLSQ) & $\begin{array}{l}- \\
48.31532\end{array}$ & $\begin{array}{l}- \\
3.504727\end{array}$ & $\begin{array}{l}- \\
2.893956\end{array}$ & $\begin{array}{l}- \\
2.584126\end{array}$ & Stationary \\
\hline
\end{tabular}

\section{Unit Root Test Results}

In order to make sure whether the variables are stable, the cointegration analysis must be carried out before the variable is tested. From table I, the absorption capacity, foreign technology introduction, domestic technology purchase and patent licensing amount at 5\%,1\%, 10\% are non stationary series, the first order difference, the original sequence at the corresponding level (less than 10\%) were tested, the original sequence stored in the unit root and is a single integer.

\section{Cointegration Test Results}

Through the ADF unit root test, the results show that the variables are a single integer, so there is a co integration relationship between the variables. In this paper, we select the absorption capacity and the amount of patent licensing, technology introduction and patent licensing, domestic technology to buy and the amount of patent licensing three Johansen cointegration tests, the test results are shown in table II. The likelihood ratio test results show that there is a co integration relationship between the absorptive capacity and the number of patents, the introduction of technology and the number of patents granted, and the purchase of technology and the level of the three variables (less than 10\%).

TABLE II Results of Johansen co integration test

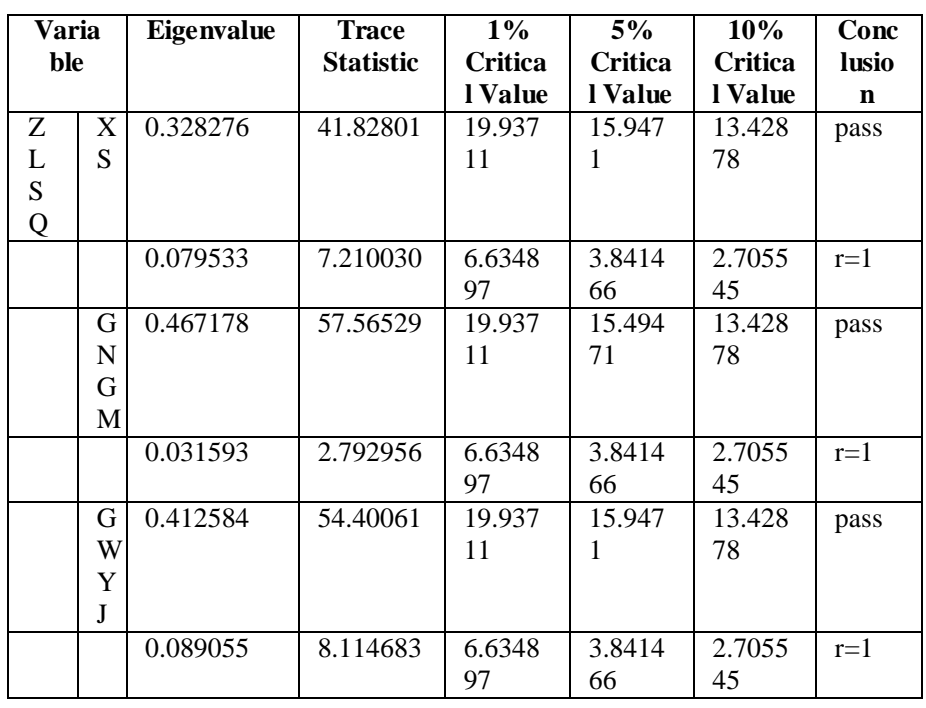

\section{E. Causality Test results}

Cointegration test results show that there is a long-term stable equilibrium relationship among the variables, but it needs to be further demonstrated to verify whether this equilibrium relationship is a causal relationship. Taking absorptive capacity as an example, there are four results amount of results between patent authorized: (1) absorption ability influence the number of authorized patents; (2) patents affect the amount of absorption capacity; (3) absorption ability affect the patent authorization, and patent authorization quantity affect the absorption capacity; the causal relation between the two, the formation of a dynamic feedback mechanism; (4) absorption ability and patent authorization does not affect mutually, there is no causal relationship between the two. There are four possible estimates of the relationship among the foreign technology introduction, the domestic technology purchase and the amount of patent licensing.

Granger causality model in the lag period, the number of $\mathrm{M}$ $=\mathrm{n}$, and the lag period of 1, 2, 3, 4. Granger 1995-2013 cointegration test results are shown in table 3 . From table 3 , it can be seen that the two-way causal relationship is formed 
between the absorption capacity and the amount of the patent licensing. For the domestic technology purchase and patent licensing, there is no causal relationship between the 1 year, when the lag period is years, the reason for the change of ZLSQ is not the GNGM change, the hypothesis that the change of ZLSQ is not the change of GNGM. In the lag period of 1 to
4 years, the GNGM change is not the Granger change of the ZLSQ reason is rejected. The change of ZLSQ was not changed by Granger at the time of 1 to 4 years, but the lag period was 1 years. The level of GWYJ was the lowest. In lagged 3, 2 years, GWYJ change is not the cause of the change in the amount of corporate technology patents are accepted.

TABLE II. RESUlts OF GRANGER CAUS Ality TeSt

\begin{tabular}{|c|c|c|c|c|c|}
\hline Null Hypothesis & lagged differences & $\mathbf{1}$ & 2 & 3 & 4 \\
\hline \multirow{2}{*}{ ZLSQ is not the Granger causality Of XS } & F statistics & 2.33789 & 1.86531 & 1.67774 & 2.10351 \\
\hline & probability & 0.0500 & 0.0742 & 0.0002 & 0.0284 \\
\hline \multirow[t]{2}{*}{$\mathrm{XS}$ is not the Granger causality Of ZLSQ } & F statistics & 8.23115 & 5.12380 & 4.03193 & 3.56607 \\
\hline & probability & 0.000003 & 0.00004 & 0.0955 & 0.0006 \\
\hline \multirow{2}{*}{ ZLSQ is not the Granger causality Of GNGM } & F statistics & 3.09346 & 1.66701 & 0.81936 & 1.51191 \\
\hline & probability & 0.0137 & 0.1164 & 0.6378 & 0.1427 \\
\hline \multirow{2}{*}{ GNGM is not the Granger causality Of ZLSQ } & F statistics & 2.48028 & 1.86642 & 2.93056 & 2.69326 \\
\hline & probability & 0.0392 & 0.0740 & 0.0031 & 0.0055 \\
\hline \multirow[t]{2}{*}{ ZLSQ is not the Granger causality Of GWYJ } & F statistics & 0.23072 & 0.4521 & 0.74404 & 1.48689 \\
\hline & probability & 0.9479 & 0.8987 & 0.7119 & 0.1523 \\
\hline \multirow[t]{2}{*}{ GWYJ is not the Granger causality Of ZLSQ } & F statistics & 2.64006 & 1.52826 & 1.26694 & 2.47746 \\
\hline & probability & 0.0298 & 0.1580 & 0.2640 & 0.0100 \\
\hline
\end{tabular}

\section{CONCLUSIONS AND DISCUSSION}

In this paper, we analyze the dynamic relationship between high tech industries in China by using the unit root test, co integration analysis and Granger causality test of the high tech industry. We can get these conclusions.

- The absorption capacity, the introduction of foreign technology, the purchase of domestic technology and the original sequence of the amount of patents are in the presence of unit root, and all of the time series, which shows that there may be a long-term stable dynamic equilibrium relationship among the variables.

- There is a long-term stable equilibrium relationship between the absorption capacity, the introduction of foreign technology, the purchase of domestic technology and the amount of patent licensing by the co integration analysis.

- The change in the amount of the patent licensing has caused the change of absorptive capacity and domestic technological purchase, and the impact of the purchase of domestic technology has been greatly reduced with the extension of the lag period. And the change of the amount of patent licensing has not caused the change of foreign technology introduction, in the late period of the extension of the significant level in the rise, the enterprise based on knowledge innovation and the introduction of foreign technology innovation mechanism. The change of absorption capacity, the introduction of foreign technology and the domestic technology purchase caused the change of the amount of patent licensing. So that regarding the introduction of foreign technology and domestic technology as the main channel of external technology acquisition and the amount of patent licensing as new product development capabilities, there is no interaction between the formations of feedback mechanism.

In the open environment, we should strive to enhance the independent R \& D investment, increase the intensity of external technology acquisition, but also study how to effectively enhance the absorptive capacity of enterprises, thus making foreign technology and domestic technology get high efficiency of production. To enhance the development of new product development capabilities, and promote the steps on the positive interactive feedback mechanism among the development of foreign technology, domestic technology and new product development.

\section{REFERENCE}

[1] JEFFERSON G,HUAGZ,GUAN X, etal. R \& D and technology transfer: firm - level evidence from Chinese industry, William Davidson Institute, Working Paper 582,2003.

[2] Tsai K.-H. ,Hsieh M.-H., Hultink E. J. External technology acquisition and product innovativeness: The moderating roles of R\& D investment and configurational context $[\mathrm{J}]$. Journal of Engineering and Technology Management,2011,28(3): 184-200.

[3] LIU X,BUCK T. Innovation performance and channels for international technology spillovers: evidence from Chinese high tech industries [J] . Research Policy,2007(36):355-366.

[4] CHEN Ao Research on ConnectionMechanism Between Technology Transfer, Product Innovation and Patent Output-Based on the Data of Large an Medium sized Industry Enterprises During 19912006[J].R\&D Management,2009,06.

[5] LI Wuwei. Technology Transfer, aptation\& Assimilation and product Innovation Performance-Based on rovincial Panel Data of Chinese High - tech Industries[J]. Science and Technology Management Rsearch,2012,09.

[6] Cohen W M ,Levinthal D A. Absorptive Capacity: A New Perspective on Learning and Innovation U]. Administrative Science Quarterly,1990(35): 128-152.

[7] Cohen,W. M. \& Levinthal,D. Innovation and Learning:The Two Faces of R\&D [J] . Economic Journal,1989,99:569 - 596. 
[8] Zahra,A. S. \& George,G. Absorptive Capacity: A Review Reconceptualization, and Extension [J] . Academy of Management Review,2002,27(2): 185-203.

[9] Kogut, B. \& Zander, U. Knowledge of the Firm, Integration Capabilities, and the Replication of Technology $[\mathrm{J}]$. Organization Science, 1992,3(3):383 - 397.

[10] Nelson, R. R., \& Winter, S. G.An evolutionary theory of economic change. Cambridge, MA: Harvard University Press. (1982). 